\title{
O PROCESSO DE CRIAÇÃO DE UMA HORTA TERAPÊUTICA: RELATO DE EXPERIÊNCIA
}

\section{Franciéli da Costa Rubert ${ }^{1}$; Aline Oliveira da Silva ${ }^{2}$, Simoni Machado Santini ${ }^{3}$; Taís Radiske ${ }^{4}$; Patricia Cristiane da Costa Dutra ${ }^{5}$; Minéia Weber Blattes ${ }^{6}$}

\section{RESUMO}

As Estratégias de Saúde da Família (ESF) têm papel fundamental nas ações de prevenção e promoção em saúde, inclusive na área de saúde mental. A adoção de estratégias que visem suavizar e inovar nos atendimentos têm sido cada vez mais utilizadas pelos profissionais de saúde. O presente artigo é um relato de experiência vivenciado pela autora farmacêutica residente em saúde mental em uma ESF. Tratase de um estudo qualitativo que visa relatar a criação de uma horta como instrumento terapêutico e meio para o desenvolvimento de rodas de conversa. A horta como instrumento terapêutico tem se demonstrado promissora, principalmente para aqueles usuários com quadros depressivos e de ansiedade.

Palavras-chave: saúde mental; atenção primária em saúde, depressão, ansiedade.

Eixo Temático: Atenção Integral e Promoção à Saúde

\section{INTRODUÇÃO}

Após a reforma psiquiátrica o cuidado ao paciente portador de transtorno mental sofreu alterações e o modelo hospitalocêntrico e médico centrado deu lugar as equipes multiprofissionais e uma nova forma de assistência, aquela mais centrada nas individualidades do sujeito e na sua autonomia (DE SOUZA; MIRANDA, 2017).

\footnotetext{
${ }^{1}$ Farmacêutica - Residente em Saúde Mental - UFN. francielirubert7@gmail.com.

${ }^{2}$ Assistente Social - Residente em Saúde Mental - UFN lineoliveiradasilva@gmail.com

3 Terapeuta Ocupacional - Residente em Saúde Mental - UFN simonisntini@hotmail.com

${ }^{4}$ Psicóloga- Residente em Saúde Mental - UFN tais_radiske@hotmail.com

${ }^{5}$ Enfermeira - Preceptora do campo da ESF patycristiane@gmail.com

${ }^{6}$ Orientadora - Tutora da Residência Multiprofissional - UFN mweber@ufn.edu.br
} 
As estratégias de saúde da família (ESF), criadas a fim de descentralizar a atenção primária em saúde (APS), são fundamentais no processo de cuidado contínuo de seus usuários, com isso elas assumem um papel importante no desenvolvimento de estratégias que visem a promoção em saúde, incentivando os usuários a adotarem bons hábitos (GOSENHEIMER et al., 2018).

Com o objetivo de humanizar e tornar mais leve e dinâmico os espaços de atendimento e a relação entre os usuários e os profissionais do serviço, muitos espaços de saúde tem optado por implantar a horticultura como terapia, essa técnica ajuda os pacientes tanto física como psiquicamente. Estima-se que a horticultura como forma de terapia alivia o estresse, fomenta a interação social e promove o bem-estar. A forma como a horticultura é estruturada favorece que rodas de conversas com assunto fitoterápicos e alimentação saudável sejam trabalhadas. (DE SOUZA; MIRANDA, 2017). Com base neste exposto, este trabalho tem o objetivo de relatar a experiência da implantação de uma horta como instrumento terapêutico de promoção em saúde em uma ESF.

\section{METODOLOGIA}

Este trabalho constitui um relato de experiência, vivenciado pela autora farmacêutica residente em saúde mental da Universidade Franciscana em uma estratégia de saúde da família juntamente com as demais residentes ao implementar uma horta a fim de desenvolver estratégias de promoção em saúde. As intervenções acontecem de forma individual e na área externa da ESF, os assuntos mais pertinentes ali tratados são o uso de fitoterápicos, práticas alimentares saudáveis, autocuidado e bons hábitos.

\section{RESULTADOS E DISCUSSÕES}

Após a reforma psiquiátrica no Brasil os Centro de Atenção Psicossociais (CAPS) foram criados a fim de dar um outro olhar e humanizar o atendimento aos portadores de transtornos mentais. Os serviços de APS que são considerados as portas de entrada do SUS (Sistema Único de Saúde), também foram incluídos nas 
políticas de saúde mental (DE OLIVEIRA et al., 2009). A atenção básica é peça chave na organização das redes de atenção psicossocial (RAPS) e desempenha um papel fundamental no acompanhamento desses usuários, visando ações de prevenção e promoção em saúde mental (GERBALDO et al., 2018). A equipe de residentes em saúde mental foi inserida em uma ESF, serviço pertencente a APS, tendo em vista o potencial desse campo de atuação, que possibilita desenvolver ações de promoção e prevenção em saúde no próprio território e assim, diminuir a sobrecarga dos serviços especializados, garantindo a prevenção do agravamento dos casos e o acompanhamento dos mesmos.

Compete as ESF promover ações de prevenção à saúde e atuar a nível de território reconhecendo os direitos dos indivíduos e buscando um modelo que ressignifique as experiências de viver (DANILEVICZ, 2020). Apesar do constante evoluir da tecnologia muitos usuários dos serviços buscam um atendimento mais leve, mais humanizado, voltado para o sujeito e não para a doença, um atendimento que fuja do modelo médico-centrado (MATTOS; DA SILVA; RODRIGUES, 2018). Por entender que as ESF surgiram como uma forma de reorganização da atenção básica em saúde e que essa possui um papel de extrema importância na busca da integridade da saúde de seus usuários entende-se que as equipes devam programar suas intervenções em saúde considerando as necessidades locais e de forma que contemplem práticas de cuidado a toda a família e comunidade e que assim, permitam que os próprios usuários sejam protagonistas no seu processo de cuidado.

Para Mattos e colaboradores, 2018 as atividades da horta terapêutica devem ser embasadas e construídas nos mesmos moldes das previstas na política nacional de práticas integrativas e complementares (PNPIC). O profissional de saúde é o responsável conduzir e preparar essas atividades. A construção e o cultivo na horta têm por finalidade promover a saúde, o bem-estar, o contato com a natureza, a interação social e a valorização pessoal (MATTOS; DA SILVA; RODRIGUES, 2018). Considerando que muitos dos usuários atendidos pela equipe de saúde mental na ESF apresentam quadros depressivos e de ansiedade, possuem dificuldade de interação social, relatam falta de motivação e ânimo, entre outros sintomas. E a experiência positiva das hortas terapêuticas em outros serviços, optou-se pela 
criação da horta com a finalidade de favorecer a interação social, seja ela através da interação familiar ou com os profissionais de saúde. Os usuários demonstraram sentir-se bem e úteis ao realizarem as atividades da horta e apresentam motivação quanto as atividades propostas interagindo sobre 0 assunto.

Um dos maiores desafios para a implantação da horta terapêutica foi a pandemia do COVID-19 pois impossibilitou que os atendimentos fossem em grupos, o que teria favorecido a interação e permitido momentos de trocas entre os usuários do serviço.

$\mathrm{Na}$ experiência relatada por Nachtigall e colaboradores, 2021 no centro de atendimento psicossocial na cidade de Videiras mostrou que a pandemia do COVID19 limitou algumas atividades presenciais, inclusive as da horta, com isso a equipe desenvolveu um projeto de extensão virtual onde utilizaram as redes sociais e as alimentavam com vídeos e publicações sobre o assunto, incentivando seus usuários e não perdendo o vínculo com o grupo (NACHTIGALL et al., 2021).

A estratégia acima adotada parece ser satisfatória em grupos já existentes, contudo foi descartada pela equipe pois o grupo ainda não estava em andamento e não havia um vínculo entre os usuários e os profissionais. Outro fator que dificulta o desenvolvimento de estratégias com o uso de tecnologia é a alta vulnerabilidade da região em que a ESF está inserida, tendo em vista que poucos usuários têm acesso a eletrônicos e internet. Com isso optou-se pela criação da horta em um ambiente externo e que as intervenções fossem realizadas com horário marcado e de forma individual, com um usuário e um profissional de saúde, por se tratar de intervenções ao ar livre, o território não observou riscos quanto ao deslocamento dos usuários até o serviço.

No estudo de Gosenheimer e colaboradores, 2018 a horta foi construída na própria estrutura da ESF, foram utilizados materiais como pneus, terra nativa, mudas de plantas medicinais, materiais trazidos por usuários e proveniente de doações (GOSENHEIMER et al., 2018). Na experiência relatada por Grumm e colaboradores, 2017 optou-se por utilizar materiais recicláveis como litros PETS, onde foram semeadas hortaliças e plantas medicinais (GRUMM et al., 2017) 
A horta, objeto desse trabalho, foi criada no ambiente externo da ESF, com a utilização de litros PET os quais foram pendurados de forma vertical, a fim de otimizar o espaço, nesse local foram plantadas hortaliças e plantas medicinais, foram utilizados pneus para aquelas plantas maiores, as tintas serviram para a pintura de litros e pneus deixando o ambiente mais bonito e agradável. Optou-se por utilizar materiais recicláveis para assim conscientizar os usuários do serviço sobre a importância de cuidar do meio ambiente. Os temas escolhidos para as intervenções durante o processo de construção e cultivo da horta foram a fitoterapia, alimentação saudável e autocuidado.

A fitoterapia é reconhecida como um importante instrumento para fins profiláticos, curativos e paliativos e devido a isso ganhou um papel de destaque dentro da assistência farmacêutica (YONESHIGE, 2018)

Levando em consideração o papel que a fitoterapia assumiu e ainda vem assumindo dentro da sociedade e o seu reconhecimento por parte dos profissionais e órgão de saúde reconheceu-se o quão benéfico e enriquecedor seria formular rodas de conversas no espaço destinado para o cultivo das plantas medicinais visando esclarecer dúvidas, valorizar a cultura popular e promover a redução do consumo de medicamentos.

A prática de fomentar hábitos alimentares saudáveis aos usuários é de responsabilidade de todo profissional de saúde, a promoção de diálogos sobre práticas alimentares faz parte do cuidado integral à saúde (MATTOS; DA SILVA; RODRIGUES, 2018). As rodas de conversas sobre alimentação incentivam os usuários a praticarem bons hábitos, melhoram o processo de saúde/doença e incentivam os usuários a querer cultivar para o próprio consumo, reduzindo custos e favorecendo o meio ambiente.

As intervenções e as criações da horta ainda estão em processo de construção e têm por objetivo incentivar cada vez mais usuários a aderirem as dinâmicas. Outro objetivo futuro do grupo é levar as atividades de horta para a residência dos usuários como forma de auxiliar a interação familiar e disponibilizar acesso a alimentos frescos. A horta já tem demonstrado resultados positivos desde sua criação. 


\section{CONCLUSÃO}

O cuidado com a saúde dos usuários em saúde mental sofreu uma série de alterações nos últimos anos. As ESF, que surgiram com a finalidade de fortalecer a APS, desempenham um papel fundamental nesse contexto. Por elas estarem inseridas no território e possuírem um contato mais próximo com os usuários do serviço, permitem que as ações de prevenção e promoção em saúde sejam desenvolvidas e direcionadas às necessidades da comunidade.

$O$ desenvolvimento de diferentes instrumentos terapêuticos tem se apresentado como uma estratégia conveniente nos espaços de saúde, torna os atendimentos mais leves e favorece a adesão e constância de participação dos usuários. A horta como instrumento terapêutico é efetiva, tanto para os usuários que apresentam quadros de ansiedade e depressão, como também para aqueles que se sentem desmotivados e tem dificuldade de criar vínculo social. Utilizar-se da horta como instrumento para rodas de conversa sobre fitoterapia, alimentação saudável, autocuidado, entre outros, corroboram para um cuidado integral em saúde, além de promover a participação dos usuários e a troca de conhecimentos.

\section{REFERÊNCIAS}

DANILEVICZ, Vatsi Meneghel. Semeaduras: uma cartografia na atenção primária em saúde. Psicologia \& Sociedade, v. 32, 2020.

DE OLIVEIRA, Francisca Bezerra. et al. Saúde Mental na Estratégia de Saúde da Família: uma articulação necessária. Psychiatry on line Brasil, v. 14, n. 9, 2009.

DE SOUZA, Thaís Sampaio; MIRANDA, Marlene Barreto Santos. Horticultura como tecnologia de saúde mental. Revista Psicologia, diversidade e Saúde, v.4, n.6, p. 310-323, 2017. 
GERBALDO, Tiziana Bezerra. et al. Avaliação da organização do cuidado em saúde mental na atenção básica a saúde do Brasil. Trabalho, Educação e Saúde, v. 16, p. 1079-1094, 2018.

GRUMM, Pedro Fontana Moraes Bernardo. et al. Horta terapêutica no centro de atenção psicossocial de videira. X MICTI III IF Cultura, 2017

GOSENHEIMER, Gustavo Afonso. et al. A horta comunitária como uma atividade facilitadora do processo de autocuidado na atenção primária em saúde. XIX Jornada de extensão. 2018.

MATTOS, Ana Carolina Einsfeld; DA SILVA ROCHA, Luciana; RODRIGUES, Lovaine. Dialogando sobre alimentação e nutrição na saúde mental: Ações promotoras de saúde por meio de oficinas de horticultura. Revista Da Associação Brasileira De Nutrição-RASBRAN, v. 9, n. 2, p. 17-24, 2018.

NACHTIGALL, Gilson Ribeiro. et al. Atividades virtuais do projeto de extensão horta terapêutica. Brazilian Journal of Development, Curitiba, v.7, n.6, p. 60052-60060 jun. 2021

YONESHIGE, Natália Montanha. Hortoterapia: horta fitoterápica promotora de saúde implantada em uma residência terapêutica, Trabalho de conclusão de residência, São Paulo, 2018. 